\title{
Correspondence
}

\section{Diathermy machines}

TO THE EDITOR, British fournal of Ophthalmology

SIR, There must be a very large number of diathermy machines lying idle in Eye Departments all over the country since cryotherapy is now almost exclusively used for retinal detachment surgery.

May I suggest that these machines can be used as a substitute for cautery for small surface bleeding points for all types of operations. The medium point adjustable applicator seems the best and this unipolar applicator is more accurate and just as easy to use as the bipolar type of diathermy such as the Codman Mentor.

Speaking from a standpoint of little knowledge (which I hope is not too dangerous a thing) having designed a simple diathermy machine (1958), there would appear to be no danger of retinal damage as the

\section{Notes}

\section{European Ophthalmic Pathology Society}

The European Ophthalmic Pathology Society held its I 5 th annual meeting as a joint meeting with the Verhoeff Society in Washington DC, from 25 to 29 April 1976.

The scientific sessions were held at the Armed Forces Institute of Pathology and were organized by Lorenz E. Zimmerman, Head of the Ophthalmic Pathology Branch, the Armed Forces Institute of Pathology, and his staff.

A sight-seeing tour was arranged for the European participants on Sunday 25 April, followed by a reception

\section{Symposium on Colour Education}

\section{Renfrew, Scotland, I and 2 October 1976}

A symposium on colour education will be held at the Normandy Hotel, Renfrew. It will include papers on aspects of the use of colour in education for teachers and educationalists in addition to papers covering the basic principles of colour science and language and technology for artists, designers, and colour technologists.

\section{Course in Contact Lens Technology}

\section{Houston, Texas, 2 to 4 December 1976}

The Department of Ophthalmology, Baylor College of Medicine, Houston, Texas, announces its annual course in contact lens technology.

The course is open to all ophthalmologists, residents in ophthalmology, and technicians sponsored by an ophthalmologist. Attendance is limited to enable current is small and the duration of contact short.

There is the obvious disadvantage of having another bulky instrument in the theatre and attaching a pad to the patient but coagulation of bleeding points appears to be satisfactory and positive.

Yours faithfully, J. GIBSON MOORE

Barnet Area Health Authority,

Edgware General Hospital,

Edgware,

Middlesex, HA8 OAD

20 fuly 1976

\section{Reference}

MOORE, J. GIBSON (1958) Brit. F. Ophthal., 42, 245 in the evening at the Mayflower Hotel.

A concert was given by the National Symphony Orchestra in the concert hall of the famous Kennedy Centre on the Tuesday night, and a reception and banquet took place in the Presidential Room of the Mayflower Hotel on Wednesday 28 April 1976.

The next meeting of the European Ophthalmic Pathology Society will be held in Munich, West Germany, in June 1977, when Professor Otto-Erik Lund will be the Organizing Secretary.

Further details and application forms for registration may be obtained from the Hon. Secretary of the Colour Group (Great Britain) (Scottish Section): Dr A. R. Hill, Glasgow College of Technology, Department of Ophthalmic Optics, North Hanover Place, Glasgow $\mathrm{G}_{4}$ OBA. participation in the practical sessions by all participants. For further information write to David Paton, MD, Professor and Chairman, Department of Ophthalmology, Baylor College of Medicine, I 200 Moursund, Houston, Texas 77025 , USA. 